\title{
The magic baby: an extremely preterm baby case from Syria
}

\begin{abstract}
Preterm birth is a globally important cause of neonatal morbidity and mortality. In developing countries, due to poor economic and social conditions, only a small percentage of extremely preterm babies survive. Here we present a case of the smallest extremely preterm baby in Syria who was born at 25 weeks gestational age and weighing 500 gram. The case describes some of the low technical and medical resources which can be used in caring for neonates in a poor resource environment.
\end{abstract}

Keywords: extremely preterm baby, intraventricular hemorrhage, gestational age, Persistent patency of the ductusarteriosus
Volume 10 Issue 5 - 2020

\author{
Leen Jamel Doya,' Dalal Saadoun,' Mada \\ Osefori,' Bana Nezha,' Adnan Dayoub² \\ 'Department of Pediatrics, Tishreen University, Syria \\ 2Professor of Neonatology, Department of Pediatrics, Tishreen \\ university hospital, Syria
}

Correspondence: Leen Jamel Doya, Department of Pediatrics, Tishreen University Hospital, faculty of medicine, Syria, Tel 963992856983, Email dr.lee.doya@gmail.com

Received: August II, 2020 | Published: October 29, 2020

\section{Background}

Globally, around $5-18 \%$ of all births, or an estimated 15 million births per year, are estimated to be born preterm (before 37 weeks of gestation), ${ }^{1} 81.1 \%$ of them are in Asian and sub-Saharan African countries, $10.6 \%$ are in North America, and 6.2\% are in Europe. ${ }^{2}$ Prematurity causes more than a million newborn deaths annually. ${ }^{3}$ Preterm neonates who survive are more susceptible to develop shortterm and long-term complications. Common complications of preterm birth are respiratory distress syndrome(RDS), bronchopulmonary dysplasia, necrotis ingenterocolitis(NEC), sepsis, periventricular leucomalacia, seizures, intraventricular hemorrhage(IVH), cerebral palsy, infections, feeding difficulties, hypoxic-ischaemic encephalopathy, and visual and hearing problems. ${ }^{4}$

\section{Case report}

An extremely preterm male infant was born at 25 weeks gestational age, weighing $500 \mathrm{~g}$ by a spontaneous vaginal delivery after prolonged rupture of fetal membranes (PROM) for a week. He was the third child of a 38 years old mother. During pregnancy, the mother had a first trimester genital bleeding. she had a urinary tract infection a week before the delivery which was treated with antibiotics until birth. Dexamethasone was given to the mother before delivery for fetal lung maturation. The baby was born in a good condition with an Apgar score of 6 at birth and 9 at $5 \mathrm{~min}$.

After birth, the premature infant was admitted to the neonatal intensive care unit (NICU). The physical examination at admission, the length $34 \mathrm{~cm}$, head circumference $23 \mathrm{~cm}$, and abdominal circumference $21.5 \mathrm{~cm}$. He was vitally stable with prematurity signs correlated to the gestational age. The baby was given oxygen via a nasal cannula to maintain saturation in the normal ranges.

The patient underwent several investigations. The white blood cell count (WBC) was $10800 \mathrm{cell} / \mathrm{mm}^{3}$, differential count polymorphs $51 \%$, lymphocytes $41 \%$, hemoglobin $(\mathrm{Hb}) 18.6 \mathrm{~g} / \mathrm{dl}$, platelets (PLT) $280000 / \mathrm{mm}^{3}$, C-reactive protein (CRP) was $31 \mathrm{mg} / \mathrm{l}$. Other liver function tests, kidney function tests, electrolytes, and arterial blood gas were normal. There was no bacterial growth in blood and urine culture. chest X-ray (C-X-Ray) was normal.
Intravenous antibiotics, intravenous fluids, and parenteral nutrition were given to the baby. The baby had an umbilical catheter inserted using an aseptic technique which provided good intravenous access for the first 10 days of life.

Prophylactic aminophylline was given to decrease the risk of apnoea of preterm baby. On the third day of hospitalization, the child was weaned off oxygen, and enteral feeding was initiated. Routine cranial ultrasound was performed which was normal. An echocardiography showed a Persistent patency of the ductusarteriosus(PDA) measured $4 \mathrm{~cm}$ with normal pulmonary arterial pressure. A fluid restriction and acetaminophen were performed.

On the tenth day of life, the baby developed coffee-ground vomiting with abdominal distension (increase in abdominal circumference by $1.5 \mathrm{~cm}$ ) and elevation in inflammatory markers. Abdominal X-ray (A-X-ray) showed expansion of the intestinal nudity, noting the presence of edema in the wall. He was kept nil by mouth for 5 days and was maintained on intravenous fluids, and antibiotics. After clinical, radiological, and laboratory criteria improved, eternal feeding was restarted via nasogastric tube.

The baby developed an oxygen need on day 19 with normal $\mathrm{C}-\mathrm{X}$ ray and low hemoglobin value ( $\mathrm{HB} 5 \mathrm{~g} / \mathrm{dl})$. A blood transfusion was performed. Cranial ultrasound showed grade II intraventricular hemorrhage (IVH). Throughout the baby's time in the unit, his mother was taught about kangaroo care and encouraged to attend the unit as frequently as possible to provide him breast milk via nasogastric tube.

The milk amount was gradually increased. The baby was on full oral feeding by day 28 of life. Multiple vitamins, iron, therapeutic erythropoietin were given with frequent hemoglobin monitoring. Heart and brain ultrasounds were repeated and showed normal findings. Routine funduscopic and hearing examinations were performed and showed normal findings.

The baby was discharged from the unit on day 90 of life with a good general condition, and weight of $1400 \mathrm{~g}$. Currently, the child is two years and two months old with a good dynamic spiritual development and normal language skills. 


\section{Discussion}

To our knowledge, this is the first case of an extremely preterm baby in our country and region. NICU in our institution is one of the advanced units in Syria which provide high levels of preservation of premature babies despite of the poor economic condition where conservative medical procedures are often the only possible steps. Administration of antenatal steroids to mothers going into preterm labor is a routine practice. The role of antenatal steroids reduces the incidence of RDS, IVH, and NEC in premature infants. ${ }^{5}$ Aminophylline has been shown to reduce the incidence of idiopathic apnea in pretermbabies. ${ }^{6}$ Kangaroo mother care (KMC) has been estimated to reduce neonatal mortality and morbidity, particularly from infection. ${ }^{7}$

In premature infants, digestive problems are a serious and often fatal problem. Feeding breast milk significantly reduces the risk of digestive problems compared with formula feeding. ${ }^{8}$ Premature babies suffer from many life-threatening complications due to delayed maturity. PDA is a major cause of morbidity and mortality in premature infants in which the ductus arteriosus (a vessel connecting the pulmonary artery to the descending aorta) fails to close. Medical management of PDA in premature infants is comprised of fluid restriction and cyclo-oxygenase inhibitors such as indomethacin and ibuprofen. Recently, intravenous acetaminophen can be used for closure of PDA. ${ }^{9}$ IVH is most common in premature babies, especially very low birth weight babies. IVH can lead to death in brain cells near the bleeding. It can also cause increasing pressure in the head which could be life-threatening. Prevention by using Corticosteroids in preterm birth is the most effective method of preventing IVH in developing countries. ${ }^{10}$

In summary, despite the development of life in preterm infants around the world, this was the first case of a premature baby 25 gestational weeks in Syria where we have bad economic conditions and limited methods. Preventive procedures have the most important role in caring for preterm infants in developing countries.

\section{Acknowledgments}

We wish to thank the medical officer, doctors in neonate intensive care unit department who cared about the boy and laboratory assistants in Tishreen University Hospital laboratory who were doing the laboratory analysis.

\section{Funding}

None.

\section{Conflicts of interest}

The authors have no conflicts of interest to declare.

\section{References}

1. Blencowe H, Cousens S, Oestergaard MZ, et al. National, regional, and worldwide estimates of preterm birth rates in the year 2010 with time trends since 1990 for selected countries: a systematic analysis and implications. Lancet. 2012; 379(9832):2162-2172.

2. Beck S, Wojdyla D, Say L, et al. The worldwide incidence of preterm birth: a systematic review of maternal mortality and morbidity. Bull World Health Organ. 2010;88(1):31-38.

3. Lawn JE, Gravett MG, Nunes TM, et al. Global report on preterm birth and stillbirth (1 of 7): definitions, description of the burden and opportunities to improve data. BMC Preg Childb. 2010;10(S1):S1.

4. Glass HC, Costarino AT, Stayer SA, et al. Outcomes for extremely premature infants. Anesth Analg. 2015;120(6):1337-1351.

5. Elimian A, Verma U, Canterino J, et al. Effectiveness of antenatal steroids in obstetric subgroups.Obstet Gynecol. 1999; 93(2):174-179.

6. Henderson-Smart DJ, De Paoli AG. Methylxanthine treatment for apnoea in preterm infants.Cochrane Database Syst Rev. 2010;8 (12):CD000140.

7. Lawn JE, Mwansa-Kambafwile J, Horta BL, et al. Kangaroo mother care' to prevent neonatal deaths due to preterm birth complications. Int J Epidemiol. 2010;39 (1):i144-154.

8. Tudehope DI. Human milk and the nutritional needs of preterm infants. J Pediatr. 2013;162(3):17-25.

9. Mezu-Ndubuisi OJ, Agarwal G, Raghavan A, et al. Patent ductus arteriosus in premature neonates. Drugs. 2012;72(7):907-916.

10. Ballabh P. Intraventricular hemorrhage in premature infants: mechanism of disease. Pediatr Res. 2010;67(1):1-8. 